\title{
Nuclear factor erythroid 2-related factor 2 modulates HER4 receptor in ovarian cancer cells to influence their sensitivity to tyrosine kinase inhibitors
}

Ibrahim H. Kankia ${ }^{1,3}\left(\mathbb{C}\right.$, Poornima Paramasivan ${ }^{1}\left(\mathbb{0}\right.$, Matthew Elcombe ${ }^{1}$, Simon P. Langdon ${ }^{2}(\mathbb{0}$, Yusuf Y. Deeni $^{1,4^{*}}$

\author{
${ }^{1}$ Division of Health Sciences, School of Applied Sciences, Abertay University, Dundee DD1 1HG, UK \\ ${ }^{2}$ Cancer Research UK Edinburgh Centre and Edinburgh Pathology, Institute of Genetics and Cancer, University of Edinburgh, \\ Edinburgh EH4 2XU, UK \\ ${ }^{3}$ Department of Biochemistry, Faculty of Natural and Applied Sciences, Umaru Musa Yar'adua University, Katsina PMB \\ 2218, Nigeria \\ ${ }^{4}$ Department of Microbiology and Biotechnology, Faculty of Science, Federal University Dutse, Dutse PMB 7156, Nigeria
}

*Correspondence: Yusuf Y. Deeni, Department of Microbiology and Biotechnology, Faculty of Science, Federal University Dutse, Dutse PMB 7156, Nigeria.y.deeni@abertay.ac.uk; yy.deeni@fud.edu.ng

Academic Editor: Gennaro Daniele, Agostino Gemelli University Policlinic, Italy

Received: November 11, 2020 Accepted: February 25, 2021 Published: April 30, 2021

Cite this article: Kankia IH, Paramasivan P, Elcombe M, Langdon SP, Deeni YY. Nuclear factor erythroid 2-related factor 2 modulates HER4 receptor in ovarian cancer cells to influence their sensitivity to tyrosine kinase inhibitors. Explor Target Antitumor Ther. 2021;2:187-203. https://doi.org/10.37349/etat.2021.00040

\begin{abstract}
Aim: Nuclear factor erythroid 2-related factor 2 (NRF2) is a key component in the cell's response to oxidative and electrophilic stress and is a transcription factor regulating the expression of a collection of anti-oxidative and cytoprotective genes. Human epidermal growth factor receptor 4 (HER4/erbB4) regulates growth and differentiation in many cancer types. Here, NRF2 and HER4 receptor interactions were investigated in a panel of ovarian cancer cell lines.

Methods: Pharmacological [tert-butylhydroquinone (tBHQ) and retinoid/rexinoid, bexarotene] and genetic [small interfering RNA (siRNA)] manipulations were used to activate or inhibit NRF2 function in the cell line panel (PE01, OVCAR3, SKOV3). Activity of the HER-targeted tyrosine kinase inhibitors, erlotinib (ERL) and lapatinib (LAP), was evaluated after NRF2 activation.

Results: While tBHQ increased the levels of both phosphorylated-NRF2 (pNRF2) and HER4 in PE01, OVCAR3 and SKOV3 cells, bexatorene and NRF2-target siRNA treatment decreased pNRF2 and total HER4 levels. The tBHQ-dependent pharmacological activation of NRF2 attenuated the therapeutic effectiveness of ERL and LAP. Analyses of gene expression data from a HER4 driven reporter system and in vitro or in vivo cancer models, support NRF2 regulation of HER4 expression.

Conclusions: These results support the presence of signaling interaction between the NRF2 and HER4 receptor pathways and suggest that intervention modulating this cross-talk could have anticancer therapeutic value.




\section{Keywords}

Cancer, ovarian, nuclear factor erythroid 2-related factor 2, HER4-receptor, regulation, rexinoid, erlotinib, lapatinib

\section{Introduction}

Nuclear factor erythroid 2-related factor 2 (NRF2) is a basic leucine zipper protein that regulates the cell's defense to oxidative stress by activing transcription of batteries of anti-oxidant genes [1-3]. NRF2 is a master regulator of multiple genes and a key factor for cytoprotection including anti-tumour effects, neuroprotection and anti-inflammatory response [1, 4, 5]. Located in the cytoplasm, NRF2 degrades under normal and unstressed conditions, but in the presence of oxidative stress, it moves to the nucleus where it dimerises with macrophage activating factor (Maf) proteins, then binds to antioxidant response elements (AREs) and initiates transcription of anti-oxidative genes $[1,3,6,7]$. Previously identified activators of NRF2 include tertbutylhydroquinone (tBHQ) [8] while inhibitors include the retinoid bexarotene $[9,10]$.

The human epidermal growth factor receptor 4 (HER4/erbB4) is a cell surface receptor and member of the epidermal growth factor receptor (EGFR) tyrosine kinase family. This receptor family play major roles in cancer growth and progression [11-14]. HER4 was initially thought to be specific for the regulation of development, maintenance, function and behaviour of the central nervous system [15-21]. However, many studies have identified HER4 to be relevant to carcinogenesis, cancer treatment and prognosis [22-32]. In ovarian cancer, high levels of HER4 have been associated with chemoresistance in both cell line models [33] and in patient samples where it has been associated with reduced overall survival [34]. HER4 can be expressed as alternatively spliced isoforms in ovarian cancer cells [33] and expression of a specific HER4 isoform, cytoplasmic (CYT)-1, has been associated with both increased cell growth and poor survival [35]. HER4 is activated by neuregulins, e.g., heregulin $(\mathrm{H})$, whereupon it can either homodimerise or heterodimerise with any other member (EGFR, HER2 or HER3) of the HER receptor family.

NRF2 has been shown to be aberrantly activated in many ovarian cancers and this is frequently associated with a loss of its inhibitory complex [36]. Overexpression of NRF2 is also found in many ovarian cancers [36-38]. NRF2 could have a direct link with HER4 via signalling pathways that include phosphatidylinositol 3-kinase (PI3K)/serine-threonine kinase (AKT)/mammalian target of rapamycin (mTOR), mitogen-activated protein kinase (MAPK), and signal transducers and activators of transcription (STAT) [1, 31, 39-41]. Previous studies in ovarian cancer cells have reported on the transcriptional regulation of HER2 and HER3 by NRF2 and showed associations between NRF2 function, HER2/HER3 signalling, reactive oxygen species (ROS) generation and glutathione depletion [40, 41]. Furthermore, Kankia et al. [10] demonstrated NRF2 regulation of HER1 expression and the modulatory effect of NRF2 on the sensitisation of ovarian cancer cells to receptor tyrosine kinases inhibitors (RTKi) and anticancer drugs targeting HER1/ HER2 receptors.

In this study, we explored the cross-talk between NRF2 and HER4 and the potential contribution of the HER4-NRF2 axis in influencing the cellular response to lapatinib (LAP) and erlotinib (ERL).

\section{Materials and methods}

\section{Cell culture}

The PE01, SKOV3 and OVCAR3 cell lines were cultured at $37^{\circ} \mathrm{C}$ in $5 \% \mathrm{CO}_{2}: 95 \%$ air in RPMI 1640 medium containing fetal calf serum (FCS, 9:1) together with glutamine (2 mM), sodium pyruvate (1 mM), streptomycin $(100 \mu \mathrm{g} / \mathrm{mL})$ and penicillin $(100 \mathrm{U} / \mathrm{mL})$. For experiments, cells were grown for $24 \mathrm{~h}$ in RPMI 1640 medium with 5\% double charcoal stripped fetal bovine serum (FBS, Fisher) replacing FBS. H- $\beta 1$ (Sigma) was prepared as a $1 \mu \mathrm{M}$ solution containing $5 \%$ trehalose and $10 \%$ FCS in phosphate buffered saline (PBS) and diluted to $1 \mathrm{nM}$ with media within experiments. tBHQ (Sigma) and bexarotene (Carbosynth) stock solutions were prepared in dimethyl sulfoxide (Fisher). 


\section{Cloning of HER4 promoter}

The HER4 promoter was isolated and cloned using a previously described method [40, 41]. The primer sequences used were HER4 forward: 5-CCGCTCGAGGAGTGGGAAATGG-AGATCAAGGTC-3' and HER4 reverse: 5'-GGACAAGTGTGA GGAAAGC-TGAGAGCCATGGCATG-3. Human DNA was extracted from cells using the DNeasy Blood and Tissue Kit (Qiagen). Genomic DNA (100 ng) was used to amplify the HER4 promoter sequences and real-time polymerase chain reaction (RT-PCR) conditions using MyFi mix (Bioline) included denaturation at $95^{\circ} \mathrm{C}$ for $7 \mathrm{~min}$ followed by 35 cycles at $95^{\circ} \mathrm{C}$ for $30 \mathrm{~s}$ for denaturation, $50^{\circ} \mathrm{C}$ for $30 \mathrm{~s}$ for annealing, and $72^{\circ} \mathrm{C}$ for $90 \mathrm{~s}$ for extension with a final extension for $10 \mathrm{~min}$ at $72^{\circ} \mathrm{C}$. The created PCR products were then run and extracted from an agarose gel (Qiagen), followed by digestion using XhoI and HindIII restriction enzymes (Promega), then ligation into pGL3 vector (Promega) to create a HER4 promoter construct (prHER4) driving the expression of luciferase gene which was then used in dual luciferase reporter assays (Promega). The cloned sequence was authenticated by sequencing (http://www.dnaseq.co.uk/) the plasmids. Lipofectamine 3000 (Life Technologies) was used to transfect the cloned plasmid into cell lines.

\section{Luciferase reporter assay}

To analyse HER4 transcriptional regulation, the HER4 promoter sequence was transfected into target cell lines. Cells $\left(2 \times 10^{5}\right.$ cells per well) were plated in triplicate wells for $18 \mathrm{~h}$, then transfected (using Lipofectamine 3000) with $1 \mathrm{mg}$ of pGL3 basic vector (Promega) with or without cloned fragments of HER4 promoter. pRL-CMV vector (Promega, $0.2 \mu \mathrm{g}$ ) was also co-transfected to serve as a measure of transfection efficiency. After $24 \mathrm{~h}$, cells were treated and protein lysates transferred to opaque white bottom 96-well plates. The firefly luciferase (from the cloned promoter) and Renilla luciferase (from the internal control) in the harvested lysates were then measured according to the manufacturer's protocol (Promega) with luminescence being measured in a luminometer (MODULUS, Promega).

\section{Cytotoxicity assay}

Cell viability was assessed with the CellTiter-Glo ${ }^{\circledR} 2.0$ assay kit (Promega). Cells were plated in 96 -well plates and left for $24 \mathrm{~h}$. After treatment with drugs as described, the plates were left for $30 \mathrm{~min}$ at room temperature. CellTiter-Glo 2.0 reagent was added at a volume equal to that of medium present in each well and cell lysis was induced by placing the plate on an orbital shaker and then incubating at room temperature for $10 \mathrm{~min}$ to stabilize the luminescent signal read by luminometer (MODULUS, Promega). The assay measures ATP which in turn indicates the level of live and metabolically active cells.

\section{Western blot analysis}

Cells were plated into $60 \mathrm{~mm}$ cell culture plates and grown until 70\% confluence. After treatment, cells were trypsinized, washed with PBS. Protein lysates were prepared using Radio-Immunoprecipitation Assay (RIPA) buffer (Pierce Biotech) together with protease and phosphatase inhibitor cocktail (Pierce Biotech) and sonicated for 2 cycles of $10 \mathrm{~s}$. After shaking on ice for $15 \mathrm{~min}$, the lysates were centrifuged $(14,000 \mathrm{~g}$ for $15 \mathrm{~min}$ ) and supernatant collected. The protein content was measured by Bradford assay (Sigma-Aldrich) using bovine serum albumin as reference. Lysates were added to sample loading buffer [NuPAGE lithium dodecyl sulfate (LDS), Invitrogen], heat denatured $\left(70^{\circ} \mathrm{C}\right.$ for $\left.10 \mathrm{~min}\right)$ and stored at $-20^{\circ} \mathrm{C}$ until used. Lysates were loaded onto Nupage Bis-Tris gels (Life Technologies) and electrophoresed at $200 \mathrm{~V}$ for 1-2 $\mathrm{h}$. Proteins were then transferred onto polyvinylidene fluoride (PVDF) membranes (GE Amersham) within the Invitrogen ${ }^{\text {TM }}$ iBlot $^{\mathrm{TM}} 2$ Dry Blotting System. Membranes were first blocked before being incubated with primary antibodies (either for $2 \mathrm{~h}$ at room temperature or overnight at $4^{\circ} \mathrm{C}$ ). Primary antibodies targeted the following: HER4 (Rabbit; Abcam, Ab32375), phosphorylated-NRF2 (pNRF2; Rabbit; Abcam, Ab76026), phospho-AKT (pAkt)Ser473 (Rabbit; Cell Signaling, Ab9271) and b-actin (Rabbit; Abcam, 801). Primary antibody incubation was followed by incubation with horseradish peroxidase (HRP)-linked secondary (anti-Rabbit; Cell Signaling, 7,074; 30 min at room temperature). Pierce enhanced chemiluminescence (ECL) 2 western blotting substrate (ThermoScientific) and reagents were then used according to manufacturer's protocol. Blots were analyzed using a Syngene G-BOX Chemi-XX6 Gel Documentation System (Synoptics, UK). Densitometry was measured using Image J software and integrated optical densitometry analysis of each band was then performed. $\beta$-actin was used as loading control and the values shown are normalized against this. 


\section{Small interfering RNA (siRNA) knockdown studies}

A specific siRNA (Hs_NFE2L2_6, Qiagen) was used to knockdown NRF2. Cells were plated in triplicate either in 24-well plates $\left(0.5 \times 10^{5}\right.$ cells $)$ or in $60 \mathrm{~mm}$ plates with cells grown on poly-L lysine coated coverslips $\left(0.5 \times 10^{6}\right.$ cells). After $24 \mathrm{~h}$, cells were then co-transfected using either $20 \mathrm{pmol}$ siRNA and $1 \mu \mathrm{g}$ of different pGL3 promoter constructs (for 24-well plates) or 75 pmol siRNA only (for $60 \mathrm{~mm}$ plates) and incubated for a further $24 \mathrm{~h}$. Cells transfected in 24-well plates were used for the dual luciferase assay while those in $60 \mathrm{~mm}$ plates were harvested for immunoblotting. In all experiments, scrambled siRNA of equivalent quantity to the NRF2-siRNA was used as a control. All transfections were used using Lipofectamine 3000 (Life Technologies).

\section{Determination of ROS and glutathione levels}

For measurement of ROS, cells $\left(2 \times 10^{4} / \mathrm{mL}\right)$ were plated in triplicate in opaque 96 -well plates in phenol redfree medium $(100 \mathrm{~mL})$. After $18 \mathrm{~h}$, an equal volume $(100 \mathrm{~mL})$ of a 2',7'-dichlorofluorescein diacetate (DCFDA, $50 \mathrm{mM}$ ) solution was added to each well and left to react for $45 \mathrm{~min}$ at $37^{\circ} \mathrm{C}$. ROS levels were measured by fluorescence using excitation $(485 \mathrm{~nm})$ and emission $(535 \mathrm{~nm})$ spectra in a multiplate reader (MODULUS, Promega). For normalization, cells were stained with Coomassie blue stain (Sigma) for $1 \mathrm{~h}$ then washed with distilled $\mathrm{H}_{2} \mathrm{O}$. To release the dye, sodium dodecyl sulphate (10\% solution) was added with 10 min shaking. Absorbance was read at $595 \mathrm{~nm}$ in the above multiplate reader.

For measurement of glutathione, cells $\left(1 \times 10^{4} / \mathrm{mL}\right)$ were plated in white clear bottom 96-well plates and left for $18 \mathrm{~h}$. Media were removed from the wells. The glutathione (GSH)/GSSG-Glo ${ }^{\mathrm{TM}}$ Assay (Promega) was used according to the manufacturer's protocol. Total glutathione lysis reagent (50 mL) was added to each well and lysates were transferred to a 96-well opaque plate. Plates were shaken at room temperature for $5 \mathrm{~min}$. Luciferin Generation Reagent $(50 \mathrm{~mL}$ ) was added to each well and plates shaken and left at room temperature for $30 \mathrm{~min}$. Luciferin Detection Reagent $(100 \mathrm{~mL})$ was added and plates were shaken for $15 \mathrm{~min}$. Luminescence was then measured using a luminometer (MODULUS, Promega).

\section{Bioinformatic methods}

Microarray data from the Gene Expression Omnibus (GEO, https://www.ncbi.nlm.nih.gov/geo/) repository was mined to retrieve gene expression data in response to ERL and LAP treatments. Datasets obtained from GEO were GSE116445, GSE116442 [42]; GSE33072 [43]; GSE80316 [44]; GSE67051 [45]. The statistical analysis of the gene expression variances obtained was undertaken using the GEO's analytical tool, GEO2R, that utilizes R programming and Bioconductor packages, from which the fold change of gene expression was calculated and then heat maps were created.

\section{Statistical analysis}

Statistical analyses were performed using Graph pad. The significance values of the differences of pooled results were determined by either independent-tests or one-way analysis of variance (ANOVA) followed by post hoc Tukey's tests. Significance was defined as *: $P<0.05,{ }^{* *}: P<0.01,{ }^{* * *}: P<0.001$ and ${ }^{* * * *}: P<0.0001$.

\section{Results}

\section{Activation of NRF2 increases expression of HER4}

We first investigated whether HER4 expression could be regulated by NRF2. To achieve this, we created a luciferase transcriptional reporter construct using the proximal promoter region of HER4 and evaluated the transcriptional expression in a group of ovarian cancer (PEO1, OVCAR3 and SKOV3) cell lines. The comparison was made with HER3, which has been shown to be regulated by NRF2 [40]. All three cell lines demonstrated an increased basal level of luciferase activity (Figure 1A). Upon addition of the NRF2 activator, tBHQ there was a concentration-dependent increase in HER4 promoter driven transcriptional activity in all cell lines. A similar pattern of response to tBHQ was observed in an MCF7 breast cancer cell line AREc32 [8] stably transfected with cis-elements of the antioxidant response (Figure 1B). To assess protein levels, western blot analysis was used to demonstrate that tBHQ $(100 \mu \mathrm{M})$ treatment produced increased levels of pAkt, pNRF2 and total HER4 levels, which was most evident in OVCAR3 cells and less obvious in PEO1 and SKOV3 cell lines (Figure 1C). These results suggest that phosphorylation and activation of NRF2 protein caused upregulation 
of HER4 levels. Taken together, these observations imply that the NRF2 and HER4 pathways might be subject to co-regulatory mechanisms partly mediated by pAkt.
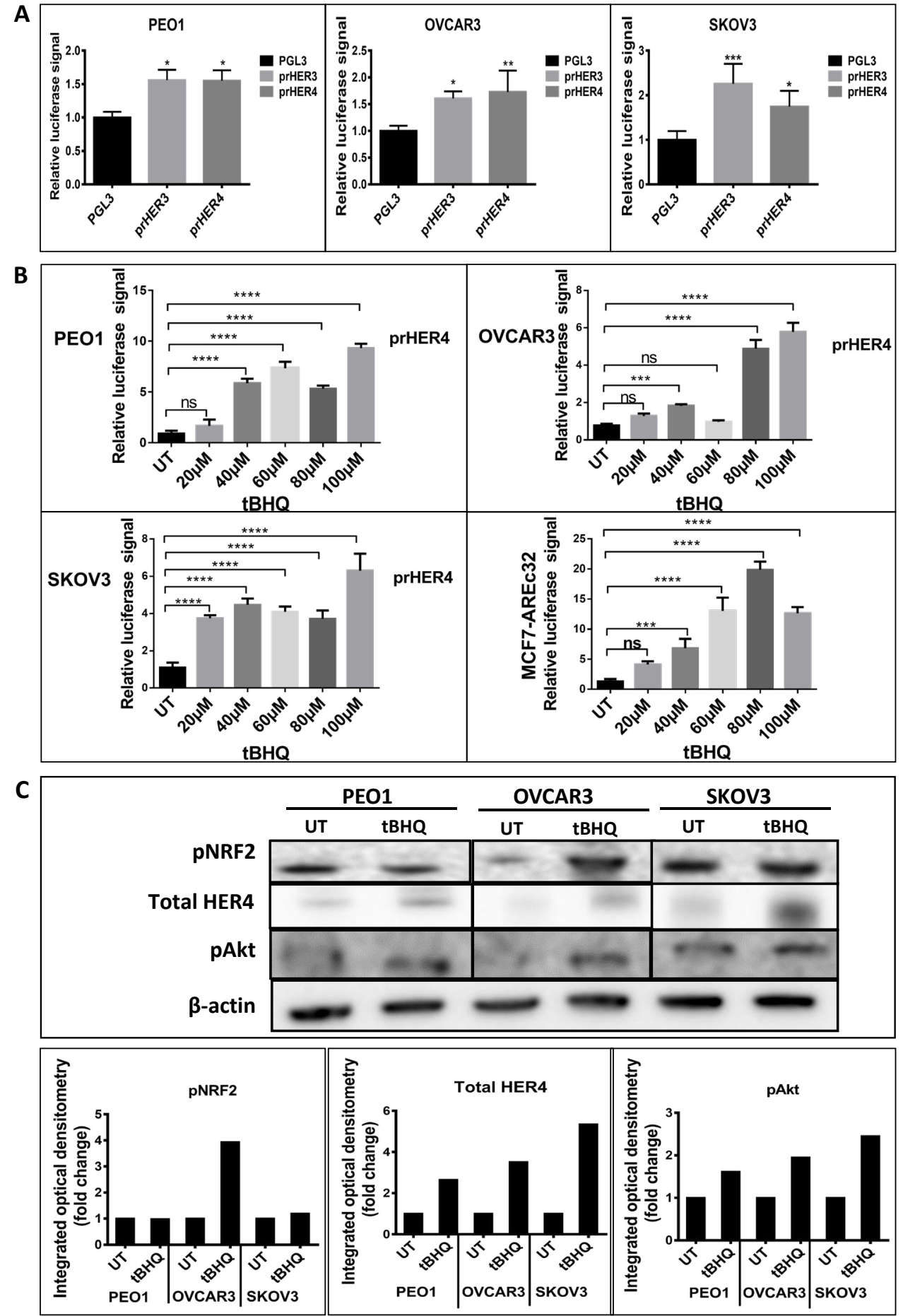

Figure 1. NRF2 regulation of HER4 expression. (A) Ovarian cancer cell lines demonstrate basal transcription of HER3 and HER4 respectively. Cell lines were transfected with either control pGL3 vector or pGL3 vector with fragments of either HER3 (prHER3) or HER4 (prHER4) promoter driving expression of luciferase. Data shown are mean of triplicates normalized to the value of pGL3 [ANOVA followed by Tukey's post hoc test $\left({ }^{*}: P<0.05,{ }^{* *}: P<0.01,{ }^{* * *}: P<0.001\right)$ ]; (B) tBHQ treatment increases transcription of HER4 in a dose dependent manner. MCF7-AREc32 contains stably cloned $8 \times$ cis-ARE driving NRF2 dependent expression of luciferase gene [8]. Means \pm standard deviation (SD) of triplicates normalized to the value of untreated (UT) are shown [ANOVA followed by Tukey's post hoc test ${ }^{* * *}: P<0.001$ and ${ }^{* * * *}: P<0.0001$; ns $=$ non-significant)]; (C) western analysis following $24 \mathrm{~h}$ treatment with tBHQ $(100 \mu \mathrm{M})$ indicated increased HER4 and pAkt expression in all cell lines. Bar charts indicate fold-changes of expression in $\mathrm{BH} \mathrm{Q}$ treated cells versus UT cell

\section{Inhibition of NRF2 causes downregulation of HER4 expression}

Since HER4 protein induction by tBHQ seemed likely a result of transcriptional upregulation, experiments were next undertaken to inhibit NRF2 with the expectation that HER4 might be down regulated. We 
examined the transcriptional level of HER4 and then the protein levels of the HER4 receptor, pNRF2 and their downstream substrate, pAkt following the inhibition of NRF2 function by bexarotene or with siRNA (Figure 2). To achieve this, the transcriptional reporter assay for HER4 receptor was used. The ovarian PE01, OVCAR3 and SKOV3 cancer cell lines were individually transfected with the reporter systems and either treated with $2.5 \mu \mathrm{M}$ bexarotene for $24 \mathrm{~h}$ or cotransfected with 75 pmol NRF2 specific siRNA for $24 \mathrm{~h}$ and $48 \mathrm{~h}$. The results indicated transcriptional downregulation of HER4 and significant repression of HER4 and decreases in both pAkt and pNRF2 levels in all 3 cell lines. The findings indicate that inhibition of NRF2 function was linked to inhibition of the HER4 pathway. This is consistent with the antioxidant response and HER4 pathways being co-regulated and with NRF2 regulating HER4 expression and protein levels.

\section{tBHQ activation of NRF2 enhances cellular proliferation and survival of ovarian cancer and attenuated} the cytotoxic and anticancer effects of LAP and ERL

Several studies have shown NRF2 to increase resistance to chemotherapeutic agents and enhance the cellular proliferation of cancer cells [8, 46-49]. Moreover, several HER-targeted tyrosine kinase inhibitors (TKIs) including LAP and ERL are used to treat HER family overexpressing (or mutant) cancers and are being evaluated against ovarian cancer [50-53]. In this part of the study the ovarian cancer cell lines, which are known to express HER family receptors and NRF2, were firstly examined for whether activation of NRF2 would modulate cellular response to LAP and ERL. The cells were grown in media containing $5 \%$ charcoalstripped FBS and $1 \mathrm{nM} \mathrm{H}$ and then treatments were undertaken. The results first showed that NRF2 activation by tBHQ alone enhanced proliferation of these cell lines (Figure 3). However, exposure of these cells to the HER receptor inhibitors, LAP and ERL, inhibited the proliferation of all the cell lines for up to $72 \mathrm{~h}$ of treatment, but with a loss of the growth inhibitory and cytotoxic effect at $96 \mathrm{~h}$. Generally, LAP appeared to be a more effective cytotoxic and a better inducer of NRF2, HER family receptors and NRF2-dependent genes (Figures 3 and 4). Pretreatment of cells with $100 \mu \mathrm{M} \mathrm{tBHQ}$ for $5 \mathrm{~h}$ prior to addition of LAP and ERL significantly protected cells from the growth inhibitory actions of these drugs. This was observed in all 3 cell lines at all treatment time points examined. These results (Figures 1-3) suggest that NRF2 activation led to cellular protection, induction of HER4 and perhaps eventual resistance to LAP and ERL whose actions are specific to inhibition of HER family receptor function. Furthermore, these findings provide support for a direct link and interaction between HER family receptor expression and NRF2 antioxidant response pathway.

\section{Genetic reprogramming and NRF2 signalling following ERL and LAP treatment}

To further support and confirm our findings, we retrieved and mined published microarray data of in vitro and in vivo gene expression studies in ovarian, lung and liver cancer models that have been treated with LAP or ERL [42-45]. First, we examined and analyzed the gene expression data on the response of ovarian cancer cells NCI-ADR-RES, OVACR-3, OVACR-4 and SK-OV-3 to ERL and LAP treatment [42], particularly in the context of dynamic changes in the NRF2 network and signalling pathway. We identified significant changes relative to control in the expression of genes within the NRF2 network following LAP or ERL therapy. Many of the differentially expressed genes in the NRF2 network [54-57] appeared to be modulated by ERL or LAP treatment at low $(100 \mathrm{nM})$ or high $(1 \mu \mathrm{M})$ concentrations. Selected changes in the NRF2 network are shown in the heatmaps (Figure 4A and B). The higher concentration of LAP or ERL used produced greater effects on gene expression changes in ascending order of magnitude in terms of down- and up-regulation of genes. Following ERL or LAP treatment, genes within the NRF2 network that markedly changed were transport, detoxification and metabolism related ABCA1, ABCA3, ABCC1, ABCG1, ABCG2, ABCG5, AKR1A1, AKR1B1, AKR1C1, AKR1C3, AKR1D1, AKR7A2, G6PD, GCLC, GCLM, HMOX1, NQ01, NQ02, SLC2A1, SQSTM1, TALD01, TXNRD1, VDAC1 and VDAC2; DNA damage and repair related BRCA1; stability, transcription and epigenetic control related BACH1, BACH2, Maf, Maf1, MafB, MafF, MafG, MafK; cell signaling, proliferation, inflammation and immunity related, AKT1, CEBPA, CEBPB, CEBPE, CEBPG, CEBPZ, ERBB1, ERBB2, ERBB3, ERBB4 and RPS6; cell cycle regulation, cell survival and death related BCL2 and MCL1. Interestingly, the expression of ERBB4 (HER4) correlates with the expression of NRF2 (NFE2L2) levels in all the cell lines when treated with either ERL or LAP. For all the cell lines used for the study, NRF2 expression appeared to be drug dose dependent and the expression of HER4 follows the NRF2 expression trend, as well as that of AKT and heme oxygenase-1 (HO-1, a well known classical NRF2-dependent gene). 


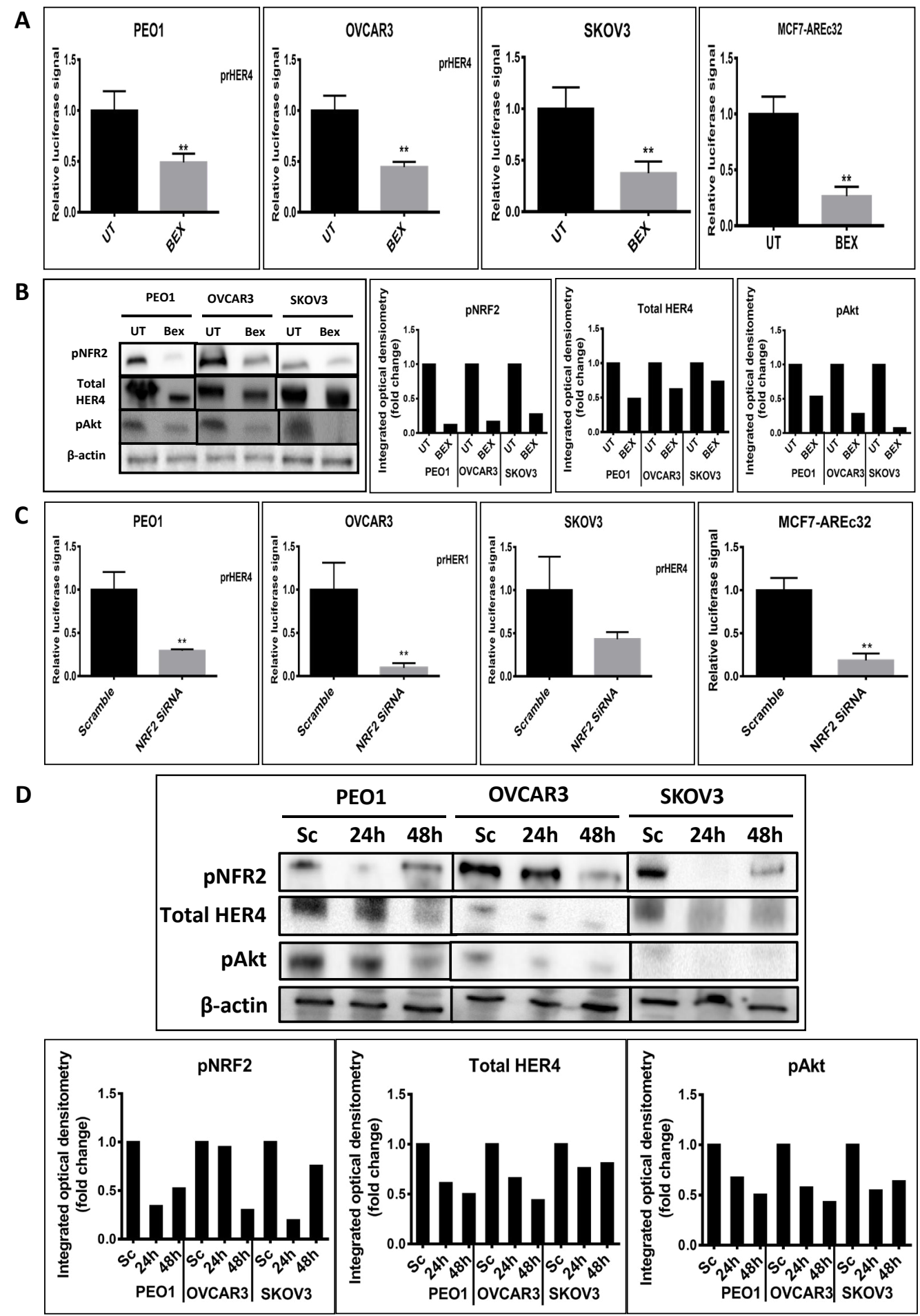

Figure 2. Inhibition of NRF2 by bexarotene or siRNA is associated with downregulation of HER4. (A) Luciferase assay demonstrating downregulation of HER4 by bexarotene in cell lines. Cells were transfected with either pGL3 basic vector or pGL3 basic vector with cloned NRF2 AREs driving the expression of luciferase gene. After $24 \mathrm{~h}$, cells were either UT or treated with $2.5 \mu \mathrm{M}$ bexarotene for a further $24 \mathrm{~h}$. Lysates were prepared and luciferase activity was measured as described in Materials and methods; (B) western analysis after treatment with bexarotene indicated decreased expression of HER4, pNRF2 and pAkt. Cells were either UT or treated with $2.5 \mu \mathrm{M}$ bexarotene for $24 \mathrm{~h}$ before being processed for western analysis. Signal quantitation is shown in the bar charts; (C) siRNA-reduction of NRF2 decreases transcription of HER4. Cells were treated with NRF2-targeted siRNA or scrambled siRNA as described in Materials and methods; (D) western blot analysis after siRNA-mediated knockdown of NRF2 demonstrated expression of HER4 receptor, pNRF2 and pAkt proteins in cell lines. Cells were either transfected with scrambled siRNA (Sc) or transfected with 75 pmol of NRF2 siRNA (Si). After $24 \mathrm{~h}$ and $48 \mathrm{~h}$, cells were processed for western analysis using indicated antibodies. $\beta$-actin was used as loading control. The bar chart indicates the expression levels as fold change. Data shown in figures $(\mathrm{A})$ and $(\mathrm{C})$ are the mean $\pm \mathrm{SD}$ of triplicates, normalized to untreated or scramble control expressed as fold change with statistical significance determined by student's $t$-test $\left({ }^{*}: P<0.05,{ }^{* *}: P<0.01\right.$ and $\left.{ }^{* * *}: P<0.001\right)$ 


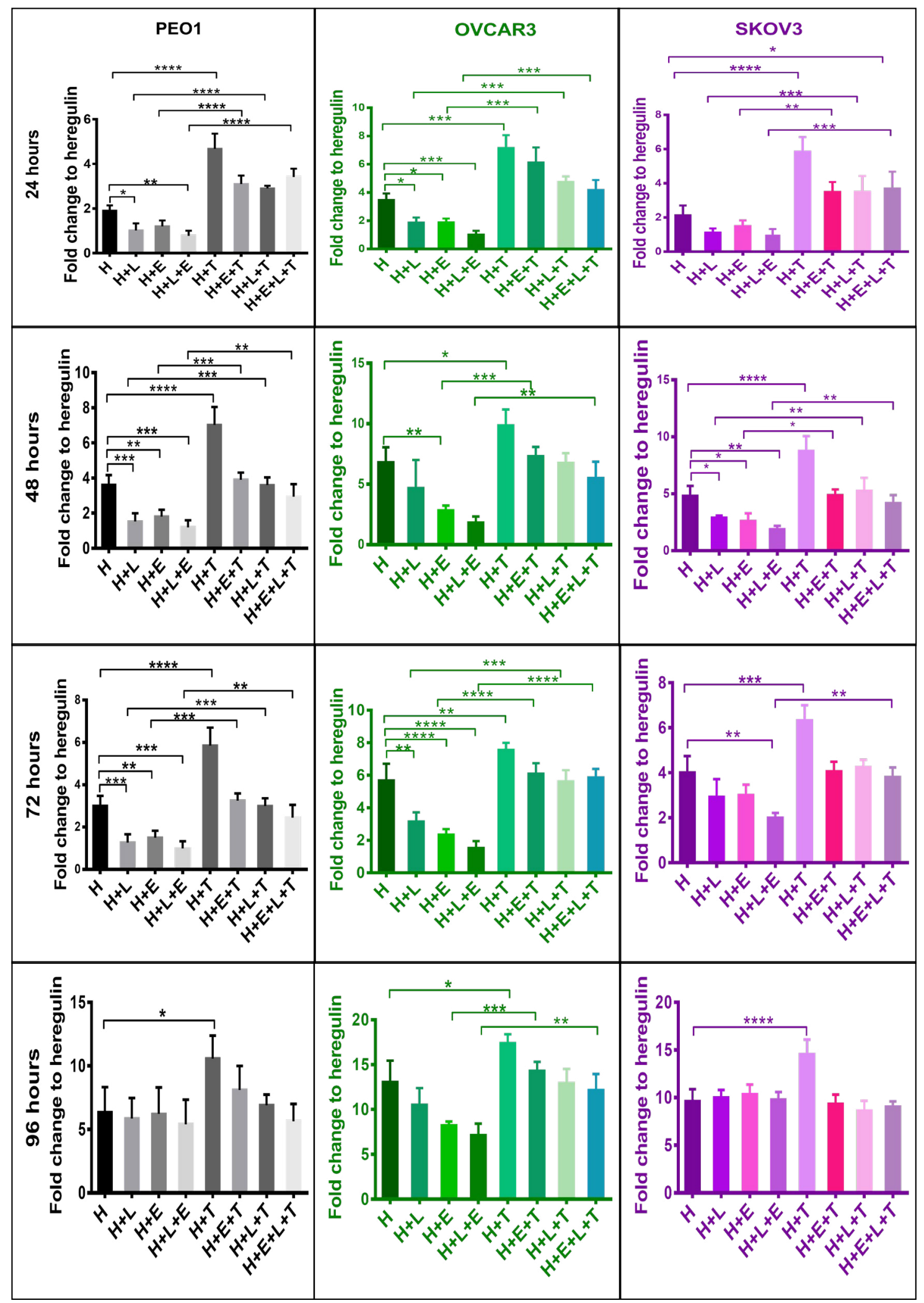

Figure 3. NRF2 activation confers cytoprotection against HER family targeting drugs, LAP (L) and ERL (E) in ovarian cancer cell lines. Cells were plated in media containing $1 \mathrm{nM} \mathrm{H}$ or treated with media containing $1 \mathrm{nM} \mathrm{H}$ and $5 \mu \mathrm{M}$ of HER family kinase inhibitors: $L A P(H+L)$, or $E R L(H+E)$, or $L A P$ and $E R L(H+L+E)$, or $100 \mu M t B H Q(H+T)$, or $t B H Q$ and $L A P(H+L+T)$, or $t B H Q$ and ERL $(H+E+T)$ or combination of both inhibitors and tBHQ $(H+E+L+T)$. tBHQ $(100 \mu M)$ was added $5 \mathrm{~h}$ in advance and prior to treatments with inhibitors. Cell survival number was assessed indirectly and relative to control by use of the CellTiter-Glo assay (Promega). Values shown are means \pm SD of triplicates adjusted relative to control. Statistical significance was calculated between $\mathrm{H}+\mathrm{L}, \mathrm{H}+\mathrm{T}$, and $\mathrm{H}+\mathrm{L}+\mathrm{T}$ groups by One-way ANOVA followed by Tukey's post hoc test according to the scale (*: $P<$ $0.05,{ }^{* *}: P<0.01,{ }^{* * *}: P<0.001$, and $\left.{ }^{* * * *}: P<0.0001\right)$ 
A

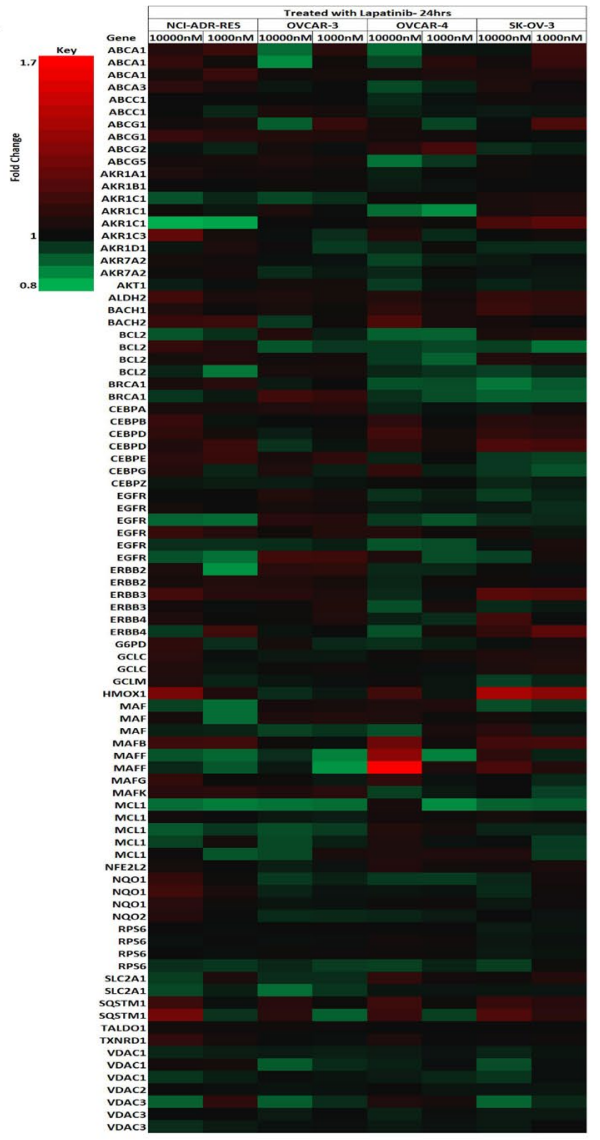

C

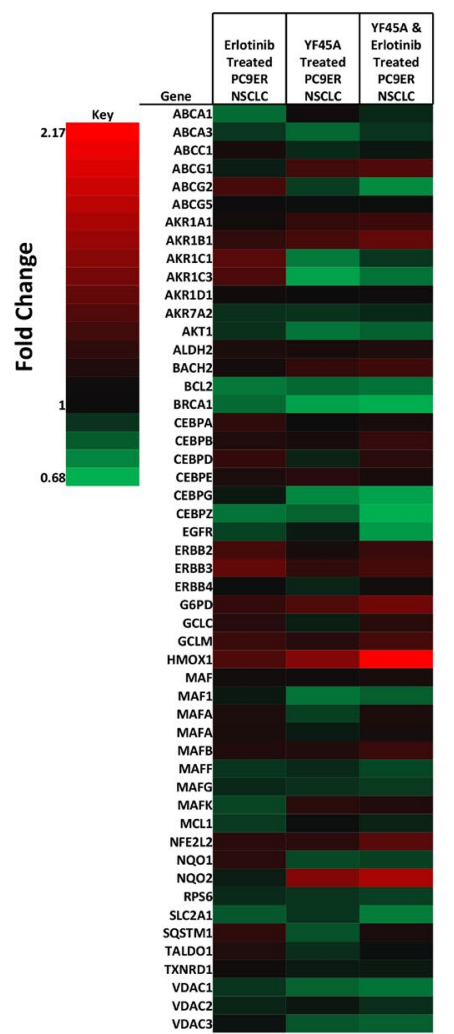

B

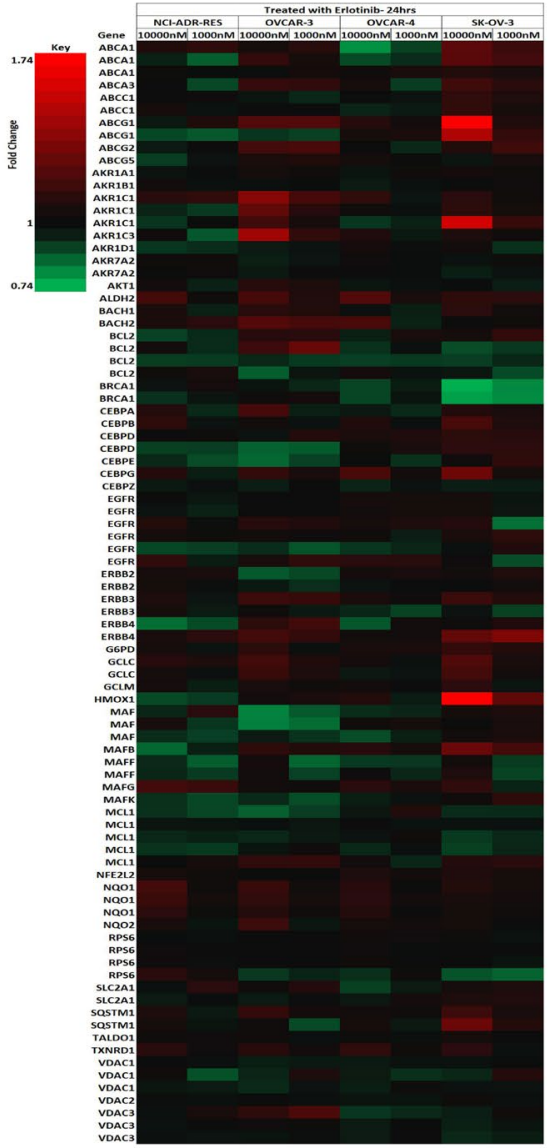

D

D

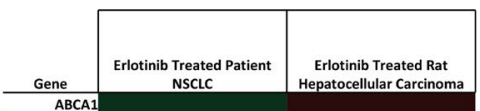

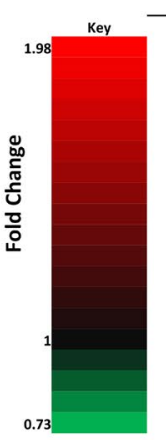

ABCC

ABCC1
ABCG1
ABCG2

ABCG

AKR1A

AKR1B1

AKR1D

AKR7A2
AKT1
BACH1

BACH

BCI

CEBPA

CEBPB

CEBPG
CEBPZ

EGFR

ERBB2
ERBB3
ERBBA

ERBB3
ERBB4
GGPD
GCLC

GCLC
GCLM

HMOK1
MAF

MAF
MAF1

MAFB

MAFG

MAFK
MCL1 1
NFE2L2

NQO1

NQO

RPS6
SLC2A1

QSTM1

VDAC

Figure 4. NRF2 network dependent molecular responses to LAP or ERL. Heatmap showing fold-change differential expression of genes within the NRF2 network relative to control treatment of a panel of ovarian cancer cells (NCI-ADR-RES, OVCAR3, OVCAR4, and SKOV3) treated for $24 \mathrm{~h}$ with (A) LAP (1 $\mu \mathrm{M}$ and $10 \mu \mathrm{M}) ;(B) E R L[1 \mu \mathrm{M}$ and $10 \mu \mathrm{M}$, significance analysis of microarrays $(S A M)$ false discovery rate $(F D R)=10 \%$ ] [43]; $(C)$ heatmap showing fold-change differential expression of genes within the NRF2 network relative to control treatment of non-small cell lung cancer (NSCLC) cell lines (PC9ER) treated for $12 \mathrm{~h}$ with ERL $(5 \mu \mathrm{M})$ or YF45A $(0.2 \mu \mathrm{M})$ alone, or combination of ERL and YF45A (SAM FDR $=10 \%)$ [44]; (D) heatmap showing foldchange differential expression of genes within the NRF2 network relative to control treatment of in vivo NSCLC patients and rat hepatocellular carcinoma xenograft tumor with ERL (SAM FDR $=10 \%$ ) [45]. Red represents increased expression and green decreased expression relative to the median of the controls 
To check whether NRF2 and HER4 follow the same expression pattern in different cell lines and cancer models, we retrieved and analyzed the microarray gene expression data and profiles of ERL resistant NSCLC PC9 cells [44] treated with ERL or histone deacetylase (HDAC) inhibitor YF454A alone or their combination (Figure 4C). The combination of ERL and HDAC inhibitor YF454A was shown to be a more effective anticancer therapy against NSCLC with EGFR-TKI resistance [44]. Interestingly we could observe that NRF2 and HER4 expression followed a similar pattern and the same order as with the ovarian cancer line models. In addition, this analysis provided further evidence for the contribution of epigenetics to the distinct mechanisms of alterations of NRF2 function by the HDAC inhibitor [41] and concomitant upregulation of the NRF2 levels in this model. Combination treatment with ERL and YF45A caused NRF2 levels to be downregulated more than with the individual/single treatments. Further, analysis of ERL treated rat hepatocellular carcinoma and NSCLC patient tissue microarray data $[43,45]$ confirmed our observed perturbations in NRF2 network by exhibiting similar trend patterns and concomitant directional expression of NRF2 and HER4 (Figure 4D) as with the ovarian (Figure 4A and B) and lung (Figure 4C) cancer cell lines. This supports and strengthens the notion that NRF2 and HER4 follow the analogous expression in ovarian, lung and liver cancer models, and plausibly NRF2 regulates HER4 expression in all these cells/tissues. This regulation of HER4 expression by NRF2 appeared to be modulated by LAP or ERL drug, which may also be a contributing determinant and basis of cellular sensitivity and response (susceptibility and resistance) of some cancers to LAP and/or ERL.

Acquired cross-resistance to LAP and increased levels of HER4, pNRF2, pAkt and NRF2-dependent H0-1 in ERL resistant PE01 (PE01/ERL) ovarian cancer cell line

To further explore the concept that NRF2 status and function in the cell could be a contributing determinant and basis of HER4 receptor expression and cellular sensitivity and response of some cancers to LAP and/or ERL, we developed an ERL resistant PE01 cell line using a previously described approach [43-45]. The mechanism of growth inhibition of ERL and LAP (Figure 5A) towards both the parental PEO1 and ERL resistant PE01/ERL ovarian cancer cell lines appeared to be associated with ROS generation (Figure 5A and B). The newly established ERL resistant PE01/ERL cell line had a decreased constitutive level of ROS (Figure 5C) and an increased constitutive total GSH level (Figure 5D) and had acquired cross-resistance to LAP (Figure 5A). Interestingly, the ERL resistant PE01/ERL cells have increased levels of HER4 (1.5-fold), pNRF2 (2.5-fold), pAkt (1.5-fold) and NRF2-dependent HO-1 (1.5-fold) relative to the parental PEO1 ovarian cancer cells (Figure 5E and F). This is consistent with the suggestion that NRF2 activation led to induction of HER4, cellular protection, and perhaps eventual resistance to ERL and LAP. Thus, these observations support the assertion that HER4 expression is regulated by NRF2 and may also be a contributing determinant and basis of cellular sensitivity and response (susceptibility and resistance) of some cancers to ERL and perhaps to LAP.

\section{Discussion}

In this study, we have demonstrated that the HER4 receptor is regulated by NRF2. NRF2 activation by tBHQ was associated with increased levels of HER4 protein while inhibition of NRF2 with the retinoid bexarotene or use of NRF2 targeted siRNA decreased HER4 expression Previous studies have demonstrated that NRF2 transcriptionally regulates HER1, HER2 and HER3 receptors $[40,41]$ and this present study now indicates that HER4 is also regulated. Pharmacological activation of NRF2 with tBHQ upregulated HER4 both at the transcriptional and protein levels. tBHQ is a known effector and activator of NRF2 [8]. The upregulation of HER4 at protein level is concomitant with increased expression of pNRF2 and pAkt. These observations were reversed following pharmacological and genetic inhibition of NRF2 with bexarotene and siRNA, respectively across all the cell lines but with different levels of response, perhaps due to differential levels of basal expression of these component molecules. Bexarotene is a rexinoid and known inhibitor of NRF2 $[9,10]$ and is Food and Drug Administration (FDA) approved for treatment of cutaneous T-cell lymphoma [58, 59].

There is increasing interest in and use of molecularly targeted inhibitors in cancer treatment, however the efficacy of these drugs is sometimes markedly reduced due to the development of resistance. Anticancer therapeutic strategies including chemotherapy can depend on ROS manipulation to induce cytotoxicity in 
cancer cells. In this study, we have shown pharmacological activation of NRF2 by tBHQ in turn increasing HER4 receptor at transcriptional and translational levels and increasing the survival of the cancer cells by reducing the cytotoxicity of the HER targeting chemotherapeutic drugs, LAP and ERL. Pharmacological and genetic inhibition of NRF2 with bexarotene and siRNA, respectively, lowered the levels of HER4 at both translational and transcriptional levels. Importantly, we have previously reported that bexarotene-dependent inhibition of NRF2 lowered expression of HER2 and HER3 receptors and enhanced the cytotoxicity of ERL and LAP in ovarian cancer cells [40].
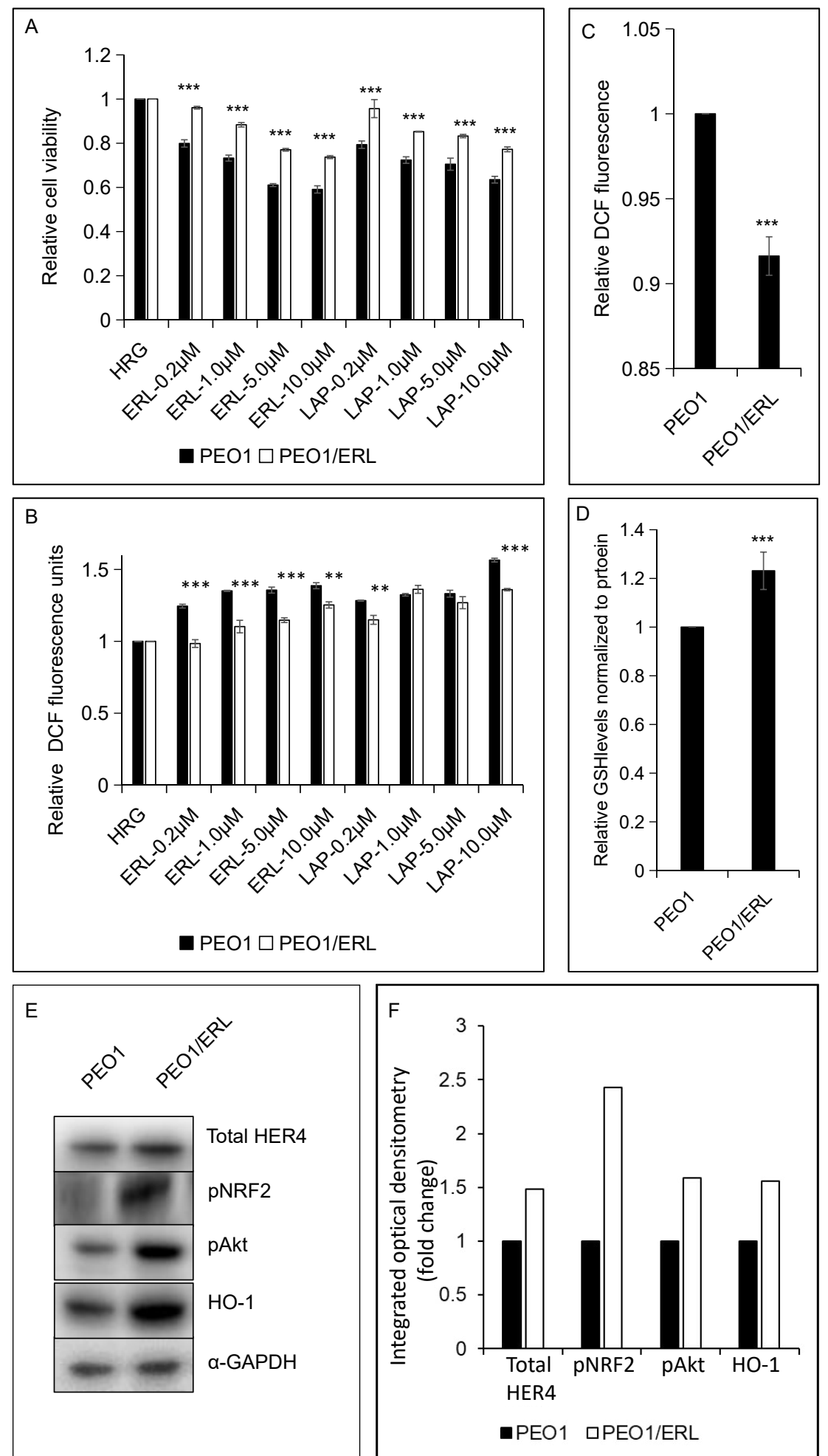

Figure 5. ERL resistant PEO1 (PEO1/ERL) ovarian cancer cell line showing ( $A$ and $B$ ) increased survival to ERL and crossresistance to LAP; (C and D) decreased basal ROS and increased basal GSH levels; and (E and F) increased basal HER4, pNRF2, pAkt and NRF2-dependent HO-1 levels relative to the parental PEO1 cell line. The bar charts (A-D) indicate the expression levels as fold change. Data shown are the mean \pm SD of triplicates, normalized to control and expressed as fold change with statistical significance determined by student's $t$-test ${ }^{* *}: P<0.01$ and $\left.{ }^{* * *}: P<0.001\right)$ 
It is contextually relevant to highlight the observation that HER4 expression can be at a high-level in cisplatin resistant ovarian cancer models [33,34]. Increased NRF2 levels, its activation and function have been implicated in the mechanisms of resistance to cisplatin [60,61]. Furthermore, HER4 expression appeared to correlate with chemotherapy resistant ovarian serous carcinoma and shortened overall survival of patients [34]. Interestingly, HER4 is becoming recognized as a good prognostic marker for breast cancer, especially for estrogen receptor (ER) positive and triple negative breast cancer (TNBC) [25, 28, 29, 32]. More specifically the favorable impact of HER4 expression was demonstrated in the observed prolonging of overall outcome and survival in trastuzumab-treated patients [22, 62]. In HER2 positive breast cancer, trastuzumab treatment and its acquired resistance induced HER4 upregulation, cleavage and nuclear translocation [22, 62]. A balance between levels of expression and spatial distribution of HER4 may define sensitivity and resistance to trastuzumab, and perhaps other HER targeting therapeutics like LAP and ERL, which may also support and strengthen our observations and results of this study. It has been demonstrated that HER 4 can be upregulated in LAP-resistant breast cancer cells and while ablation of HER4 led to apoptosis, this was not the case for HER1-3 [31]. Similar data were obtained for the response to trastuzumab. This led to the suggestion that HER4 may have a key role in HER2-positive breast cancer cells resistant to HER2 inhibitors while its role in sensitive cells is minimal [31]. HER4 appeared to modulate the PI3K/AKT pathway to confer the resistant phenotype. This is consistent with our observation that pharmacological or genetic knockdown of NRF2 reduces both HER4 and pAkt levels, and pharmacological activation of NRF2 induces both HER4 and pAkt and confers protection and survival of cancer cells following LAP and/or ERL treatments. In addition, the findings support the concept that NRF2 status and function in the cell could be a contributing determinant and basis of cellular sensitivity and response (susceptibility and resistance) of some cancers to LAP and/ or ERL.

Next, we sought evidence that NRF2 controls HER4 expression in various in vitro and in vivo cancer models. We did this by performing bioinformatic analysis of microarray data of ovarian cancer cells, NSCLC cells, rat hepatocellular carcinoma tissues and NSCLC patient tissues [44]. In our analysis we focused on the NRF2 network using a knowledge based approach as before [63]. Generally, we could demonstrate that NRF2 and HER4 follow similar expression patterns along with other NRF2 controlled antioxidant response pathway genes in both the in vitro and the in vivo models (Figure 4). Significant changes in gene expression of NRF2 and its network signalling were observed after small molecule RTKi treatment with LAP and/or ERL. The observed modulation (upregulation) of NRF2 by HDAC inhibitor YF45A alone and the reversal with the combination with ERL highlighted the notion that epigenetics may contribute to the modulation of NRF2 function and the response to small molecule RTKi treatment with ERL. This by extension complements our previous reports suggesting the role of epigenetics in the inhibition of NRF2 function by HER2-targeted antibody therapy [41].

Finally, we developed a cell line with partial resistance to ERL which also had cross-resistance to LAP. This cell line had decreased constitutive ROS and increased constitutive total glutathione, HER4, pNRF2, pAkt and NRF2-dependent HO-1 relative to wild-type PEO1 cells. These observations are consistent with NRF2 activation leading to induction of HER4, cellular protection, and resistance to ERL and LAP. These results extend and confirm the role of NRF2 in modulating the cytotoxic effect of ERL and LAP [40]. This study expands the role of NRF2 as a key element in regulating the HER family receptors, their expression and function, and in influencing the sensitivity and response to HER targeting therapies. Furthermore, these findings provide support for the existence of a direct link and interaction between ROS, HER4 expression and NRF2 antioxidant response pathway.

In conclusion, this study has provided evidence for a novel role of NRF2 in regulating the HER4 receptor and has exemplified cross talk between ROS, NRF2 and HER4 receptor. Using bioinformatic analysis, we present evidence that NRF2 and HER4 expression follow a similar pattern in various in vitro and in vivo models. Furthermore, our recent studies on the regulation of HER1, HER2 and HER3 by NRF2 to oppose HER targeted antibody therapy and chemotherapy [40, 41, 63], support the assertion that NRF2 also regulates HER4 receptor function. Results from this study showed that the pharmacological activation of NRF2 attenuates the cytotoxicity of HER targeting small molecules such as ERL and LAP. It is evident that 
NRF2 regulates HER4 receptor levels and function and may likely be contributing resistance to ERL and perhaps LAP in ovarian cancer cells. Clinical trials to date have demonstrated only very limited activity of ERL and LAP in ovarian cancer. A phase II trial of ERL as monotherapy indicated a 6\% response rate and $44 \%$ disease stabilization rate [64] and combination strategies with chemotherapy or bevacizumab have not yet proven effective [65]. For LAP, while monotherapy appears ineffective there has been interesting in its combination with carboplatin and paclitaxel [66]. Our current findings suggest that preclinical studies with NRF2 inhibitors in combination with HER inhibitors would be of interest. If effective modulation of the ROS/NRF2/HER4 axis would be a novel strategy to improve the efficacy of chemotherapeutic drugs by sensitization or by overcoming drug resistance.

\section{Abbreviations}

AKT: serine-threonine kinase

ANOVA: analysis of variance

AREs: antioxidant response elements

EGFR: epidermal growth factor receptor

ERL: erlotinib

FBS: fetal bovine serum

FDR: false discovery rate

GEO: Gene Expression Omnibus

GSH: glutathione

H: heregulin

HDAC: histone deacetylase

HER4: human epidermal growth factor receptor 4

HO-1: heme oxygenase-1

LAP: lapatinib

Maf: macrophage activating factor

NRF2: nuclear factor erythroid 2-related factor 2

NSCLC: non-small cell lung cancer

pNRF2: phosphorylated-nuclear factor erythroid 2-related factor 2

ROS: reactive oxygen species

RTKi: receptor tyrosine kinase inhibitor

SAM: significance analysis of microarrays

SD: standard deviation

siRNA: small interfering RNA

STAT: signal transducers and activators of transcription

tBHQ: tert-butylhydroquinone

TKIs: tyrosine kinase inhibitors

UT: untreated

\section{Declarations}

Acknowledgments

The authors would like to thank Professor C. Roland Wolf for kindly providing the AREc32 stable cell line. 


\section{Author contributions}

IHK and YYD contributed to the study design, designed and performed in vitro experiments, and prepared the manuscript; PP performed some in vitro experiments and contributed to the preparation of the manuscript; ME and YYD performed data mining and bioinformatics analyses; SPL provided some materials, contributed to the study design, and preparation of the manuscript; YYD coordinated, conceived and designed the study. All authors reviewed and approved the manuscript and its submission for publication.

\section{Conflicts of interest}

The authors declare that they have no conflicts of interest.

\section{Ethical approval}

Not applicable.

\section{Consent to participate}

Not applicable.

\section{Consent to publication}

Not applicable.

\section{Availability of data and materials}

Not applicable.

\section{Funding}

This work was supported by grants from The Northwood Trust, Breakthrough Breast Cancer, and PhD studentship support to IHK from Nigerian Tertiary Education (TET) Funds. The funders had no role in study design, data collection and analysis, decision to publish, or preparation of the manuscript.

\section{Copyright}

(C) The Author(s) 2021.

\section{References}

1. Kobayashi M, Yamamoto M. Molecular mechanisms activating the NRF2-Keap1 pathway of antioxidant gene regulation. Antioxid Redox Signal. 2005;7:385-94.

2. Kaspar JW, Niture SK, Jaiswal AK. NRF2: INRF2 (Keap1) signaling in oxidative stress. Free Radic Biol Med. 2009;47:1304-9.

3. Hayes JD, Dinkova-Kostova AT. The NRF2 regulatory network provides an interface between redox and intermediary metabolism. Trends Biochem Sci. 2014;39:199-218.

4. Namani A, Li Y, Wang XJ, Tang X. Modulation of NRF2 signaling pathway by nuclear receptors: implications for cancer. Biochim Biophys Acta. 2014;1843:1875-85.

5. Feng J, Zhang P, Chen X, He G. PI3K and ERK/Nrf2 pathways are involved in oleanolic acid-induced heme oxygenase-1 expression in rat vascular smooth muscle cells. J Cell Biochem. 2011;112:1524-31.

6. Yamamoto T, Kyo M, Kamiya T, Tanaka T, Engel JD, Motohashi H, et al. Predictive base substitution rules that determine the binding and transcriptional specificity of Maf recognition elements. Genes Cells. 2006;11:575-91.

7. Kimura M, Yamamoto T, Zhang J, Itoh K, Kyo M, Kamiya T, et al. Molecular basis distinguishing the DNA binding profile of NRF2-Maf heterodimer from that of Maf homodimer. J Biol Chem. 2007;282:33681-90.

8. Wang XJ, Hayes JD, Henderson CJ, Wolf CR. Identification of retinoic acid as an inhibitor of transcription factor Nrf2 through activation of retinoic acid receptor alpha. Proc Natl Acad Sci U S A. 2007;104:19589-94. 
9. McMahon M, Campbell KH, MacLeod AK, McLaughlin LA, Henderson CJ, Wolf CR. HDAC inhibitors increase NRF2-signaling in tumour cells and blunt the efficacy of co-adminstered cytotoxic agents. PLoS One. 2014;9:e114055.

10. Kankia IH, Khalil HS, Langdon SP, Moult PR, Bown JL, Deeni YY. NRF2 regulates HER1 signaling pathway to modulate the sensitivity of ovarian cancer cells to lapatinib and erlotinib. Oxid Med Cell Longev. 2017;2017:1864578.

11. Yu D, Wolf JK, Scanlon M, Price JE, Hung MC. Enhanced c-erbB-2/neu expression in human ovarian cancer cells correlates with more severe malignancy that can be suppressed by E1A. Cancer Res. 1993; 53:891-8.

12. Lipton A, Goodman L, Leitzel K, Cook J, Sperinde J, Haddad M, et al. HER3, p95HER2, and HER2 protein expression levels define multiple subtypes of HER2-positive metastatic breast cancer. Breast Cancer Res Treat. 2013;141:43-53.

13. Citri A, Yarden Y. EGF-ERBB signalling: towards the systems level. Nat Rev Mol Cell Biol. 2006;7:505-16.

14. Burden S, Yarden Y. Neuregulins and their receptors: a versatile signaling module in organogenesis and oncogenesis. Neuron. 1997;18:847-55.

15. Wen L, Lu YS, Zhu XH, Li XM, Woo RS, Chen YJ, et al. Neuregulin 1 regulates pyramidal neuron activity via ErbB4 in parvalbumin-positive interneurons. Proc Natl Acad Sci U S A. 2010;107:1211-6.

16. Sun Y, Ikrar T, Davis MF, Gong N, Zheng X, Luo ZD, et al. Neuregulin-1/ErbB4 signaling regulates visual cortical plasticity. Neuron. 2016;92:160-73.

17. Shamir A, Kwon OB, Karavanova I, Vullhorst D, Leiva-Salcedo E, Janssen MJ, et al. The importance of the NRG-1/ErbB4 pathway for synaptic plasticity and behaviors associated with psychiatric disorders. J Neurosci. 2012;32:2988-97.

18. Mei L, Xiong WC. Neuregulin 1 in neural development, synaptic plasticity and schizophrenia. Nat Rev Neurosci. 2008;9:437-52.

19. Lu Y, Sun XD, Hou FQ, Bi LL, Yin DM, Liu FM, et al. Maintenance of GABAergic activity by neuregulin 1-ErbB4 in amygdala for fear memory. Neuron. 2014;84:835-46.

20. Geng F, Zhang J, Wu JL, Zou WJ, Liang ZP, Bi LL, et al. Neuregulin 1-ErbB4 signaling in the bed nucleus of the stria terminalis regulates anxiety-like behavior. Neuroscience. 2016;329:182-92.

21. Chen YJ, Zhang M, Yin DM, Wen L, Ting A, Wang P, et al. ErbB4 in parvalbumin-positive interneurons is critical for neuregulin 1 regulation of long-term potentiation. Proc Natl Acad Sci U S A. 2010;107: 21818-23.

22. Sassen A, Diermeier-Daucher S, Sieben M, Ortmann O, Hofstaedter F, Schwarz S, et al. Presence of HER4 associates with increased sensitivity to Herceptin in patients with metastatic breast cancer. Breast Cancer Res. 2009;11:R50.

23. Paatero I, Seagroves TN, Vaparanta K, Han W, Jones FE, Johnson RS, et al. Hypoxia-inducible factor1alpha induces ErbB4 signaling in the differentiating mammary gland. J Biol Chem. 2014;289:22459-69.

24. Mohd Nafi SN, Generali D, Kramer-Marek G, Gijsen M, Strina C, Cappelletti M, et al. Nuclear HER4 mediates acquired resistance to trastuzumab and is associated with poor outcome in HER2 positive breast cancer. Oncotarget. 2014;5:5934-49.

25. Machleidt A, Buchholz S, Diermeier-Daucher S, Zeman F, Ortmann O, Brockhoff G. The prognostic value of HER4 receptor isoform expression in triple-negative and HER2 positive breast cancer patients. BMC Cancer. 2013;13:437.

26. Koutras A, Kalogeras KT, Wirtz RM, Alexopoulou Z, Bobos M, Zagouri F, et al. Evaluation of the prognostic significance of HER family mRNA expression in high-risk early breast cancer: a Hellenic Cooperative Oncology Group (HeCOG) validation study. J Transl Med. 2015;13:171.

27. Han W, Jones FE. HER4 selectively coregulates estrogen stimulated genes associated with breast tumor cell proliferation. Biochem Biophy Res Commun. 2014;443:458-63. 
28. Fujiwara S, Ibusuki M, Yamamoto S, Yamamoto Y, Iwase H. Association of ErbB1-4 expression in invasive breast cancer with clinicopathological characteristics and prognosis. Breast Cancer. 2014;21:472-81.

29. Fujiwara S, Hung M, Yamamoto-Ibusuk CM, Yamamoto Y, Yamamoto S, Tomiguchi M, et al. The localization of HER4 intracellular domain and expression of its alternately-spliced isoforms have prognostic significance in ER+ HER2- breast cancer. Oncotarget. 2014;5:3919-30.

30. Earp HS 3rd, Calvo BF, Sartor CI. The EGF receptor family--multiple roles in proliferation, differentiation, and neoplasia with an emphasis on HER4. Trans Am Clin Climatol Assoc. 2003;114:315-33.

31. Canfield K, Li J, Wilkins OM, Morrison MM, Ung M, Wells W, et al. Receptor tyrosine kinase ERBB4 mediates acquired resistance to ERBB2 inhibitors in breast cancer cells. Cell Cycle. 2015;14:648-55.

32. Bieche I, Onody P, Tozlu S, Driouch K, Vidaud M, Lidereau R. Prognostic value of ERBB family mRNA expression in breast carcinomas. Int J Cancer. 2003;106:758-65.

33. Gilmour LM, Macleod KG, McCaig A, Gullick WJ, Smyth JF, Langdon SP. Expression of erbB-4/HER-4 growth factor receptor isoforms in ovarian cancer. Cancer Res. 2001;61:2169-76.

34. Saglam O, Xiong Y, Marchion DC, Strosberg C, Wenham RM, Johnson JJ, et al. ERBB4 expression in ovarian serous carcinoma resistant to platinum-based therapy. Cancer Control. 2017;24:89-95.

35. Paatero I, Lassus H, Junttila TT, Kaskinen M, Butzow R, Elenius K. CYT-1 isoform of ErbB4 is an independent prognostic factor in serous ovarian cancer and selectively promotes ovarian cancer cell growth in vitro. Gynecol Oncol. 2013;129:179-87.

36. Van der Wijst MGP, Brown R, Rots MG. NRF2, the master redox switch: the Achilles' heel of ovarian cancer? Biochim Biophys Acta. 2014;1846:494-509.

37. Liao $H$, Zhou Q, Zhang Z, Wang Q, Sun Y, Yi X, et al. NRF2 is overexpressed in ovarian epithelial carcinoma and is regulated by gonadotrophin and sex-steroid hormones. Oncol Rep. 2012;27:1918-24.

38. Konstantinopoulos PA, Spentzos D, Fountzilas E, Francoeur N, Sanisetty S, Grammatikos AP, et al. Keap1 mutations and NRF2 pathway activation in epithelial ovarian cancer. Cancer Res. 2011;71:5091-9.

39. Yarden Y. The EGFR family and its ligands in human cancer: signalling mechanisms and therapeutic opportunities. Eur J Cancer. 2001;37 Suppl 4:S3-8.

40. Khalil HS, Langdon SP, Kankia IH, Bown J, Deeni YY. NRF2 regulates HER2 and HER3 signaling pathway to modulate sensitivity to targeted immunotherapies. Oxid Med Cell Longev. 2016;2016:4148791.

41. Khalil HS, Langdon SP, Goltsov A, Soininen T, Harrison DJ, Bown J, et al. A novel mechanism of action of HER2 targeted immunotherapy is explained by inhibition of NRF2 function in ovarian cancer cells. Oncotarget. 2016;7:75874-901.

42. Monks A, Zhao Y, Hose C, Hamed H, Krushkal J, Fang J, et al. The NCI transcriptional pharmacodynamics workbench: a tool to examine dynamic expression profiling of therapeutic response in the NCI-60 cell line panel. Cancer Res. 2018;78:6807-17.

43. Byers LA, Diao L, Wang J, Saintigny P, Girard L, Peyton M, et al. An epithelial-mesenchymal transition gene signature predicts resistance to EGFR and PI3K inhibitors and identifies Axl as a therapeutic target for overcoming EGFR inhibitor resistance. Clin Cancer Res. 2013;19:279-90.

44. Yu W, Lu W, Chen G, Chen F, Su H, Chen Y, et al. Inhibition of histone deacetylases sensitizes EGF receptorTK inhibitor-resistant non-small-cell lung cancer cells to erlotinib in vitro and in vivo. Br J Pharmacol. 2017;174:3608-22.

45. Lantermann AB, Chen D, McCutcheon K, Hoffman G, Frias E, Ruddy D, et al. Inhibition of casein kinase 1 alpha prevents acquired drug resistance to erlotinib in EGFR-mutant non-small cell lung cancer. Cancer Res. 2015;75:4937-48.

46. Tang X, Wang H, Fan L, Wu X, Xin A, Ren H, et al. Luteolin inhibits NRF2 leading to negative regulation of the NRF2/ARE pathway and sensitization of human lung carcinoma A549 cells to therapeutic drugs. Free Radic Biol Med. 2011;50:1599-609. 
47. Hayes JD, McMahon M. NRF2 and KEAP1 mutations: permanent activation of an adaptive response in cancer. Trends Biochem Sci. 2009;34:176-88.

48. Hayes JD, Ashford MLJ. NRF2 orchestrates fuel partitioning for cell proliferation. Cell Metab. 2012; 16:139-41.

49. Hayes AJ, Skouras C, Haugk B, Charnley RM. Keap1-NRF2 signalling in pancreatic cancer. Int J Biochem Cell Biol. 2015;65:288-99.

50. Ryan Q Ibrahim A, Cohen MH, Johnson J, Ko CW, Sridhara R, et al. FDA drug approval summary: lapatinib in combination with capecitabine for previously treated metastatic breast cancer that overexpresses HER-2. Oncologist. 2008;13:1114-9.

51. Roskoski R Jr. The ErbB/HER family of protein-tyrosine kinases and cancer. Pharmacol Res. 2014;79: 34-74.

52. Kuang YH, Shen T, Chen X, Sodani K, Hopper-Borge E, Tiwari AK, et al. Lapatinib and erlotinib are potent reversal agents for MRP7 (ABCC10)-mediated multidrug resistance. Biochem Pharmacol. 2010;79:154-61.

53. Geyer CE, Forster J, Lindquist D, Chan S, Romieu CG, Pienkowski T, et al. Lapatinib plus capecitabine for HER2-positive advanced breast cancer. N Engl J Med. 2006;355:2733-43.

54. Papp D, Lenti K, Modos D, Fazekas D, Dul Z, Turei D, et al. The NRF2-related interactome and regulome contain multifunctional proteins and fine-tuned autoregulatory loops. FEBS Lett. 2012;586:1795-802.

55. Malhotra D, Portales-Casamar E, Singh A, Srivastava S, Arenillas D, Happel C, et al. Global mapping of binding sites for NRF2 identifies novel targets in cell survival response through ChIP-Seq profiling and network analysis. Nucleic Acids Res. 2010;38:5718-34.

56. Hirotsu Y, Katsuoka F, Funayama R, Nagashima T, Nishida Y, Nakayama K, et al. NRF2-MafG heterodimers contribute globally to antioxidant and metabolic networks. Nucleic Acids Res. 2012;40:10228-39.

57. Bidkhori G, Narimani Z, Hosseini Ashtiani S, Moeini A, Nowzari-Dalini A, Masoudi-Nejad A. Reconstruction of an integrated genome-scale co-expression network reveals key modules involved in lung adenocarcinoma. PLoS One. 2013;8:e67552.

58. Rigas JR, Dragnev KH. Emerging role of rexinoids in non-small cell lung cancer: focus on bexarotene. Oncologist. 2005;10:22-33.

59. Garattini E, Bolis M, Garattini SK, Fratelli M, Centritto F, Paroni G, et al. Retinoids and breast cancer: from basic studies to the clinic and back again. Cancer Treat Rev. 2014;40:739-49.

60. Wu J, Bao L, Zhang Z, Yi X. NRF2 induces cisplatin resistance via suppressing the iron export related gene SLC40A1 in ovarian cancer cells. Oncotarget. 2017;8:93502-15.

61. Bao LJ, Jaramillo MC, Zhang ZB, Zheng YX, Yao M, Zhang DD, et al. NRF2 induces cisplatin resistance through activation of autophagy in ovarian carcinoma. Int J Clin Exp Pathol. 2014;7:1502-13.

62. Portier BP, Minca EC, Wang Z, Lanigan C, Gruver AM, Downs-Kelly E, et al. HER4 expression status correlates with improved outcome in both neoadjuvant and adjuvant Trastuzumab treated invasive breast carcinoma. Oncotarget. 2013;4:1662-72.

63. Khalil HS, Goltsov A, Langdon SP, Harrison DJ, Bown J, Deeni Y. Quantitative analysis of NRF2 pathway reveals key elements of the regulatory circuits underlying antioxidant response and proliferation of ovarian cancer cells. J Biotechnol. 2015;202:12-30.

64. Gordon AN, Finkler N, Edwards RP, Garcia AA, Crozier M, Irwin DH, et al. Efficacy and safety of erlotinib HCl, an epidermal growth factor receptor (HER1/EGFR) tyrosine kinase inhibitor, in patients with advanced ovarian carcinoma: results from a phase II multicenter study. Int J Gynecol Cancer. 2005;15:785-92.

65. Hirte HW. Profile of erlotinib and its potential in the treatment of advanced ovarian carcinoma. Onco Taregs Ther. 2013;6:427-35.

66. Rivkin SE, Muller C, Malmgren JA, Moon J, Iriarte D, Arthur J, et al. A Phase I/II study of lapatinib plus carboplatin and paclitaxel in relapsed ovarian and breast cancer. Clin Ovarian Cancer. 2009;2:112-7. 